\title{
Tailor-Made Conjugated Polymer Nanoparticles for Multicolor and Multiphoton Cell Imaging
}

\author{
Johannes Pecher, Johannes Huber, Martin Winterhalder, Andreas Zumbusch, ${ }^{*}$ and \\ Stefan Mecking ${ }^{*}$
}

University of Konstanz, Department of Chemistry, Universitätsstrasse 10, D-78457 Konstanz, Germany

Received July 26, 2010; Revised Manuscript Received September 5, 2010

\begin{abstract}
Sonogashira coupling of dibromo- and diethynyl-substituted benzenes and fluorenes in aqueous miniemulsion afforded colloidally stable dispersions of highly fluorescent 60-120 nm particles of poly(arylene ethynylene)s of molecular weights $M_{\mathrm{n}} 4 \times 10^{4}-2 \times 10^{5} \mathrm{~g} \mathrm{~mol}^{-1}$ with solids contents up to $15 \mathrm{wt} \%$. By covalent incorporation of diethynyl pyrrolo-pyrrole or diethynyl fluorenone in the miniemulsion polymerization the emission color of these photostable nanoparticles can be tuned from blue $\left(\lambda_{\mathrm{em} \max } 470\right)$ to orange at a given excitation wavelength due to an efficient energy transfer to these acceptors. Two-photon action cross sections of the particles amount to $10^{6}$ to $10^{7} \mathrm{GM}$. The particles from emulsion polymerization are taken up by HeLa cells without an adverse effect on the cells. Differentiation of the location in cells of particle species varying in emission color was demonstrated for both linear and two-photon excitation microscopy in the NIR regime.
\end{abstract}

\section{Introduction}

Fluorescent nanoparticles have most recently attracted interest in the contexts of optoelectronics, ${ }^{1}$ live cell imaging and biosensing. Their extraordinary fluorescent brightness and much higher fluorescence emission rates with respect to single dye molecules are beneficial for time-resolved observations or intracellular studies. Different classes of fluorescent nanoparticles have been studied, such as inorganic semiconductor quantum dots, ${ }^{2}$ dyes noncovalently encapsulated in latex ${ }^{3}$ or silica ${ }^{4}$ particles, latex particles with covalently attached dyes, ${ }^{5}$ organic nanoparticles consisting of neat dyes, ${ }^{6}$ or $\pi$-conjugated polymer nanoparticles. ${ }^{7}$ Although nanoparticles are taken up by various different types of cells, ${ }^{8}$ fluorescent nanoparticles have to meet various requirements, which also depend on the intended application. Conjugated polymer nanoparticles combine photoluminescence, high absorption coefficients and fluorescence quantum yields, and extraordinarily high nonlinear optical absorption cross sections. ${ }^{7 \mathrm{~d}, 9}$ The latter makes them attractive candidates for biological deep tissue imaging with less damaging and deeper penetrating near-infrared (NIR) excitation. ${ }^{7 \mathrm{~d}} \mathrm{By}$ contrast to most inorganic quantum dots, they do not contain cytotoxic metals such as cadmium or lead, and they have been demonstrated to be nontoxic in live cell imaging..$^{\mathrm{z}, \mathrm{e}, \mathrm{f}} \mathrm{f}$

To date, conjugated polymer nanoparticles ${ }^{10}$ have been generated mostly by postpolymerization dispersion techniques, that is, secondary emulsification or reprecipitation. ${ }^{7 \mathrm{~d}, 11}$ These techniques can rely on commercially available polymers with given specifications, and do not require equipment and expertise in organic and polymer synthesis. If required, polymers can be purified extensively after polymerization. Direct polymerization to nanoparticles, on the other hand, is not restricted to polymers with a high solubility in organic solvents, and in principle can afford a broader scope of nanoparticle structures. This requires adaption of the metal-catalyzed step-growth polymerizations necessary for the preparation of luminescent conjugated polymers to highly disperse systems, which has been reported thus

* To whom correspondence should be addressed. E-mail: andreas.zumbusch@uni-konstanz.de; stefan.mecking@uni-konstanz.de. far only for one example. ${ }^{7 b}$ Glaser coupling, which resembles an AB-type polymerization in terms of stoichiometry, yielded high molecular weight poly(arylenediethynylene) nanoparticles. Issues of concern are the stoichiometric balance at the locus of reaction in disperse systems (circumvented in the aforementioned $\mathrm{AB}$-type polymerization) as a prerequisite for obtaining substantial molecular weights in the more common $\mathrm{A}_{2}+\mathrm{B}_{2}$ polymerizations, colloidal stability of the resulting nanoparticles, and for some types of reactions catalyst stability in aqueous systems. ${ }^{12}$ We report here the preparation of aqueous nanoparticle dispersions by Sonogashira coupling and their behavior and imaging in cells.

\section{Experimental Section}

General Methods and Instrumentation. NMR spectra were recorded on a Varian Unity INOVA 400. ${ }^{1} \mathrm{H}$ and ${ }^{13} \mathrm{C}$ NMR chemical shifts were referred to the solvent signal. Dynamic light scattering was carried out on a Malvern Nano-ZS ZEN 3600 particle sizer $\left(173^{\circ}\right.$ back scattering). The autocorrelation function was analyzed using the Malvern dispersion technology software 5.10 algorithm to obtain volume and number weighted particle size distributions and polydispersity indices. For the determination of particle size, a few drops of a latex sample were diluted with about $3 \mathrm{~mL}$ of water. Gel permeation chromatography (GPC) was carried out on a Polymer Laboratories PLGPC 50 with two PLgel $5 \mu \mathrm{m}$ MIXED-C columns in THF at $40{ }^{\circ} \mathrm{C}$ against polystyrene standards. Mass spectrometric data were obtained on a Finnigan MAT8200 EI-MS. Polymer nanoparticle fluorescence quantum yields were measured on a Hamamatsu Absolute PL Quantum Yield Measurement System C9920-02 equipped with an IS detector. Linear absorption and emission spectra were recorded on a Cary 50 and a conventional fluorescence spectrometer, respectively. Confocal fluorescence images were acquired on a Zeiss LSM 510 Meta equipped with a $458 \mathrm{~nm}$ argon ion laser using a $63 \times 1.4$ oil immersion lens. Multicolor fluorescence micrographs were either recorded via two PMT detectors with the appropriate filters (Figure $2 \mathrm{a}, \mathrm{d}$ ) or via a spectrally resolved detector (Figure $2 \mathrm{~g}-\mathrm{i}$ ). Multiphoton fluorescence micrographs were recorded on a Leica TCS SP5 confocal microscope equipped with a Ti:sapphire laser (see below) at $780 \mathrm{~nm}$ excitation.

Nanoparticle Synthesis. In a $100 \mathrm{~mL}$ round-bottom flask, $500 \mathrm{mg}$ SDS were dissolved in $50 \mathrm{~mL}$ of degassed water. In a screw-cap vial, 
Table 1. Composition of Polymerization Mixtures in Table 3

\begin{tabular}{|c|c|c|c|c|}
\hline entry & structure $^{a}$ & $\begin{array}{c}\text { monomers } \\
(u \mathrm{~mol})\end{array}$ & monomers (mg) & $\begin{array}{c}\text { catalyst } \\
(\mathrm{mg})\end{array}$ \\
\hline poly-1 & H-alt-G & $200 / 200$ & $76.5 / 99.7$ & 4.5 \\
\hline poly-2 & B-alt-E & $1000 / 1000$ & $438.7 / 586.3$ & 22.7 \\
\hline poly-3 & $\begin{array}{c}\text { (B-co-I)-alt- } \\
(\mathbf{A}-c o-\mathbf{C})\end{array}$ & $970 / 970 / 30 / 30$ & $\begin{array}{c}425.5 / 532.0 / \\
9.8 / 10.1\end{array}$ & 22.7 \\
\hline poly-4 & B-alt-(F-co-D) & $500 /$ & $219.4 / 241.4 / 6.7$ & 11.4 \\
\hline poly-5 & B-alt-(A-co-D) & $1000 / 990 / 10$ & $438.7 / 543.0 / 6.7$ & 22.7 \\
\hline
\end{tabular}

${ }^{a}$ For designation of monomers, cf. Supporting Information.

under nitrogen atmosphere, appropriate amounts of the respective monomers (see Table 1) were mixed. $\left[\mathrm{Pd}\left(\mathrm{PPh}_{3}\right)_{4}\right](1 \mathrm{~mol} \%)$ and catalytic amounts of $\mathrm{CuI}$ (ca. $100 \mu \mathrm{g}$ ) were added, followed by the addition of $1.00 \mathrm{~g}$ toluene and $0.50 \mathrm{~g}$ diisopropylamine. Solids were dissolved, aided by an ultrasound bath. The monomer mixture was added to the surfactant solution by spraying into the surfactant solution with a syringe with a small diameter cannula. The mixture was ultrasonicated for $2 \mathrm{~min}$, yielding a stable miniemulsion, followed by gentle stirring at $50{ }^{\circ} \mathrm{C}$ for $72 \mathrm{~h}$ in an oil bath under rigorous exclusion of oxygen. The resulting dispersion was stirred, open to air, overnight and then filtered over glass wool.

For determination of polymer molecular weights (Table 3 and Figure S8), an aliquot of dispersion was precipitated by addition to excess methanol. The amount of polymer obtained corresponded to complete conversion of the monomers to higher molecular weight polymer within experimental error $(>97 \%)$. The latter is also evidenced by the methanol supernatant being colorless and not fluorescing signficantly. Low molecular weight oligomers expected to be soluble in methanol would fluoresce intensly.

Determination of Two-Photon Action Cross Sections. The particles two-photon action cross sections $\sigma_{2} *=\sigma_{2} \times \mathrm{QY}$ were determined by measuring the two-photon excited fluorescence intensities of the aqueous nanoparticle dispersions relative to two-photon absorption standards according to (1), with $F_{2}$ the fluorescence intensity, $\varphi$ the differential quantum efficiency, and $\lambda_{\text {reg }}$ the fluorescence registration wavelength. Indices $r$ and s stand for the reference and the sample, respectively. ${ }^{19}$

$$
\sigma_{2, \mathrm{~s}}=\frac{F_{2, \mathrm{~s}}\left(\lambda_{\text {reg }}\right) C_{\mathrm{r}} \varphi_{\mathrm{r}}\left(\lambda_{\text {reg }}\right)}{F_{2, \mathrm{r}}\left(\lambda_{\text {reg }}\right) C_{\mathrm{s}} \varphi_{\mathrm{s}}\left(\lambda_{\text {reg }}\right)} \sigma_{2, \mathrm{r}}
$$

Fluorescence spectra excited from 720 to $870 \mathrm{~nm}$ in $10 \mathrm{~nm}$ steps were recorded on a custom-made microscope by focusing a Ti:sapphire laser into the liquid samples through a $40 \times$ air lens and collecting the reflected fluorescence light on a spectrally resolved EMCCD camera. Fluorescence intensities were obtained by integration over a $3 \mathrm{~nm}$ spectral window of the emission spectra of the samples and the references, respectively. Fluorescence quantum yields were determined on a Hamamatsu Absolute PL Quantum Yield Measurement System C9920-02, from which differential quantum yields could be obtained by integration over the respective $3 \mathrm{~nm}$ spectral window. Concentrations of the dispersions were calculated on the basis of their solids contents and particle sizes, assuming a particle density of $1 \mathrm{~g} \mathrm{~mL}^{-1}$. For details of the method and instrumentation, see Supporting Information.

Photobleaching Studies. On a confocal laser setup, fluorescence images of fixed HeLa cells labeled with poly-1, poly-2, or poly-4, respectively, were collected every $6 \mathrm{~s}$ while continuously illuminating the sample for $500 \mathrm{~s}$ by excitation at $458 \mathrm{~nm}$ (also cf. ref 13). Normalized fluorescence intensity of individual images was plotted as a function of exposure time (Figure S5). The fluorescence intensity of the individual image was calculated using Zeiss LSM 510 AIM software (version 4.2 SP 1) and normalized by initial intensity ( $t=0 \mathrm{~s}$ ).

Cell Culture Procedures. An adherent HeLa 229 cell culture line was maintained in Dulbecco's modified Eagle's medium (GIBCO, Invitrogen) supplemented with $10 \%$ fetal calf serum (FCS, Biochrom AG), $100 \mathrm{U} / \mathrm{mL}$ penicillin- $100 \mu \mathrm{g} / \mathrm{mL}$ streptomycin (GIBCO, Invit-
Table 2. Amounts of Conjugated Polymer Nanoparticle Dispersions Used for Cell Labeling Experiments

\begin{tabular}{cccc}
\hline entry & $V$ (as-prepared dispersion; $\mu \mathrm{L})$ & $V\left(\mathrm{H}_{2} \mathrm{O} ; \mu \mathrm{L}\right)$ & $V$ (medium; $\mu \mathrm{L})$ \\
\hline poly-1 & 3.5 & & 247 \\
poly-2 & 2.0 & & 248 \\
poly-4 & 1.0 & 4.0 & 245 \\
\hline
\end{tabular}

rogen), and $2 \mathrm{mM} \mathrm{L-glutamine} \mathrm{(GIBCO,} \mathrm{Invitrogen).} \mathrm{Cultures} \mathrm{were}$ maintained at $37{ }^{\circ} \mathrm{C} / 5 \% \mathrm{CO}_{2}$ in a TC-treated cell culture flask (Corning, $75 \mathrm{~cm}^{2}$ ) and routinely passaged at $85-95 \%$ confluency by removing culture medium, washing cells $(1 \times \mathrm{PBS})$, trypsinization (GIBCO, Invitrogen, $1 \mathrm{~mL}, 3 \mathrm{~min}, 37{ }^{\circ} \mathrm{C}$ ), removal of trypsin solution by centrifugation (5 min, $1000 \mathrm{rpm}$ ), resuspension in growth medium, and reseeding at a concentration of approximately $2 \times 10^{5}$ cells $/ \mathrm{mL}$.

Cells being passaged were seeded on $16 \mathrm{~mm}$ cover glass circles in 12-well TC-treated microplates (Costar 3512) at approximately $1.0 \times$ $10^{5}$ cells/well $(1 \mathrm{~mL} / w e l l)$, and allowed to grow for $24 \mathrm{~h}$ at $37^{\circ} \mathrm{C} / 5 \%$ $\mathrm{CO}_{2}$. Appropriate amounts of conjugated polymer nanoparticle dispersions (pure or diluted with $\mathrm{H}_{2} \mathrm{O}$ ) were mixed with growth medium to result in total volumes of about $250 \mu \mathrm{L}$ (Table 2), which were added to the respective cell-containing wells. After incubation for $18 \mathrm{~h}$ (37 ${ }^{\circ} \mathrm{C} / 5 \% \mathrm{CO}_{2}$ ), cells were fixed with $4 \%$ paraformaldehyde (in $1 \times \mathrm{PBS}$ ) for $10 \mathrm{~min}$, washed 3 times with $1 \times \mathrm{PBS}$, and then mounted to microscope slides using mounting medium (Aqua Poly/Mount, Polysciences). Optionally, fixed cells were incubated with a second species of conjugated polymer nanoparticles ( $3 \mu \mathrm{L}$ of poly- 1 and $1 \mu \mathrm{L}$ of poly-2 and poly-3, respectively) in $1.5 \mathrm{~mL} 1 \times$ PBS for $15 \mathrm{~min}$, washed two times with $1 \times$ PBS, and then mounted to microscope slides.

Labeling of suspended cells was achieved by adding a mixture of $40 \mu \mathrm{L}$ of dispersion poly- 1 and $460 \mu \mathrm{L}$ of medium to $1 \mathrm{~mL}$ of cell suspension $\left(1 \times 10^{6}\right.$ cells $\left./ \mathrm{mL}\right)$ for an incubation time of $30 \mathrm{~min}$ at 37 ${ }^{\circ} \mathrm{C}$. Cells were collected by subsequent centrifugation ( $5 \mathrm{~min}, 1000$ rpm) and resuspended in fresh growth medium at approximately $2 \times$ $10^{5}$ cells $/ \mathrm{mL}$. Labeled cells were seeded on $16 \mathrm{~mm}$ cover glass circles in 12-well TC-treated microplates (Costar 3512), allowed to grow for $24 \mathrm{~h}$ at $37{ }^{\circ} \mathrm{C} / 5 \% \mathrm{CO}_{2}$, and then fixed with $4 \%$ paraformaldehyde (in $1 \times$ PBS) for $10 \mathrm{~min}$, washed three times with $1 \times \mathrm{PBS}$, and then mounted to microscope slides using mounting medium (Aqua Poly/ Mount, Polysciences).

\section{Results and Discussion}

Nanoparticle Synthesis. As an $\mathrm{A}_{2}+\mathrm{B}_{2}$ step-growth reaction, Sonogashira coupling provides access to poly(arylene ethynylene)s with a broad range of microstructures and optical properties due to the alternating arrangement of the $\mathrm{A}_{2^{-}}$and $\mathrm{B}_{2}$-derived repeat units. For polymerization, $\left[\mathrm{Pd}\left(\mathrm{PPh}_{3}\right)_{4}\right]$ catalyst precursor and a catalytic amount of $\mathrm{CuI}$ were added to a stoichiometric mixture of the dihalo- and dialkyne-substituted monomers in a small amount of toluene and diisopropylamine, and the mixture was added to an aqueous surfactant solution. Ultrasonication yielded a miniemulsion. The mixture was gently stirred under a protective gas atmosphere at an elevated temperature for several days. Polymerization occurred in the droplets to yield highly fluorescent nanoparticles with sizes of $60-120 \mathrm{~nm}$ of polymers with high molecular weights (Table 3, Scheme 1, and Figure S8). Over an observation period of more than one year, colloidal stability was fully retained also at relatively high concentrations exceeding $1 \mathrm{wt} \%$ solids content, as observed by dynamic light scattering (DLS). Polymerization of amphiphilic moieties provided additional steric stabilization of the particles (poly-1).

In the above polymerization procedure, a minimum of $\mathrm{CuI}$ was employed to avoid any fluorescence quenching in the resulting latex. The amount of toluene employed is critical. In 
Table 3. Characteristic Data of Polymer Nanoparticle Dispersions ${ }^{a}$

\begin{tabular}{ccccccc}
\hline entry & $M_{\mathrm{n}} \times 10^{4}{ }^{b}\left(\mathrm{~g} \mathrm{~mol}^{-1}\right)$ & $M_{\mathrm{w}} \times 10^{5}{ }^{b}\left(\mathrm{~g} \mathrm{~mol}^{-1}\right)$ & $\mathrm{QY}^{c}(\%)$ & $\lambda_{\max }{ }^{d}(\mathrm{~nm})$ & solids content $(\%)^{\text {size }^{e}(\mathrm{~nm})}$ & $\mathrm{PDI}^{f}$ \\
\hline poly-1 & 4.4 & 4.9 & 5 & 501 & 0.28 & 64 \\
poly-2 & 6.6 & 3.2 & 3 & 484 & 1.54 & 0.236 \\
poly-3 & 18.0 & 3.8 & 38 & 522 & 1.63 & 0.132 \\
poly-4 & 7.8 & 4.6 & 46 & 585 & 1.60 & 124 \\
poly-5 & 8.6 & 3.4 & 62 & 585 & 1.60 & 0.191 \\
\hline
\end{tabular}

${ }^{a}$ Reaction conditions: $50{ }^{\circ} \mathrm{C} ; 72 \mathrm{~h} ; 1 \mathrm{~mol} \%\left[\mathrm{Pd}\left(\mathrm{PPh}_{3}\right)_{4}\right] ;$ catalytic amount of Cul; $0.5 \mathrm{~g}$ of $\operatorname{Pr}_{2} \mathrm{NH} ; 1 \mathrm{~g}$ of toluene; $50 \mathrm{~mL}$ of $1 \%$ SDS aqueous solution; further details, cf. Experimental Section, Table 1. ${ }^{b}$ Determined by GPC in THF at $40{ }^{\circ} \mathrm{C}$ vs polystyrene standards. ${ }^{c}$ Absolute quantum yield. ${ }^{d}$ Emission maxima (for $398 \mathrm{~nm}$ excitation). ${ }^{e}$ Volume average particle sizes determined by dynamic light scattering. ${ }^{f}$ Polydispersity index (PDI) determined by dynamic light scattering.

Scheme 1. Polymers Prepared in the Form of Aqueous Nanoparticle Dispersions

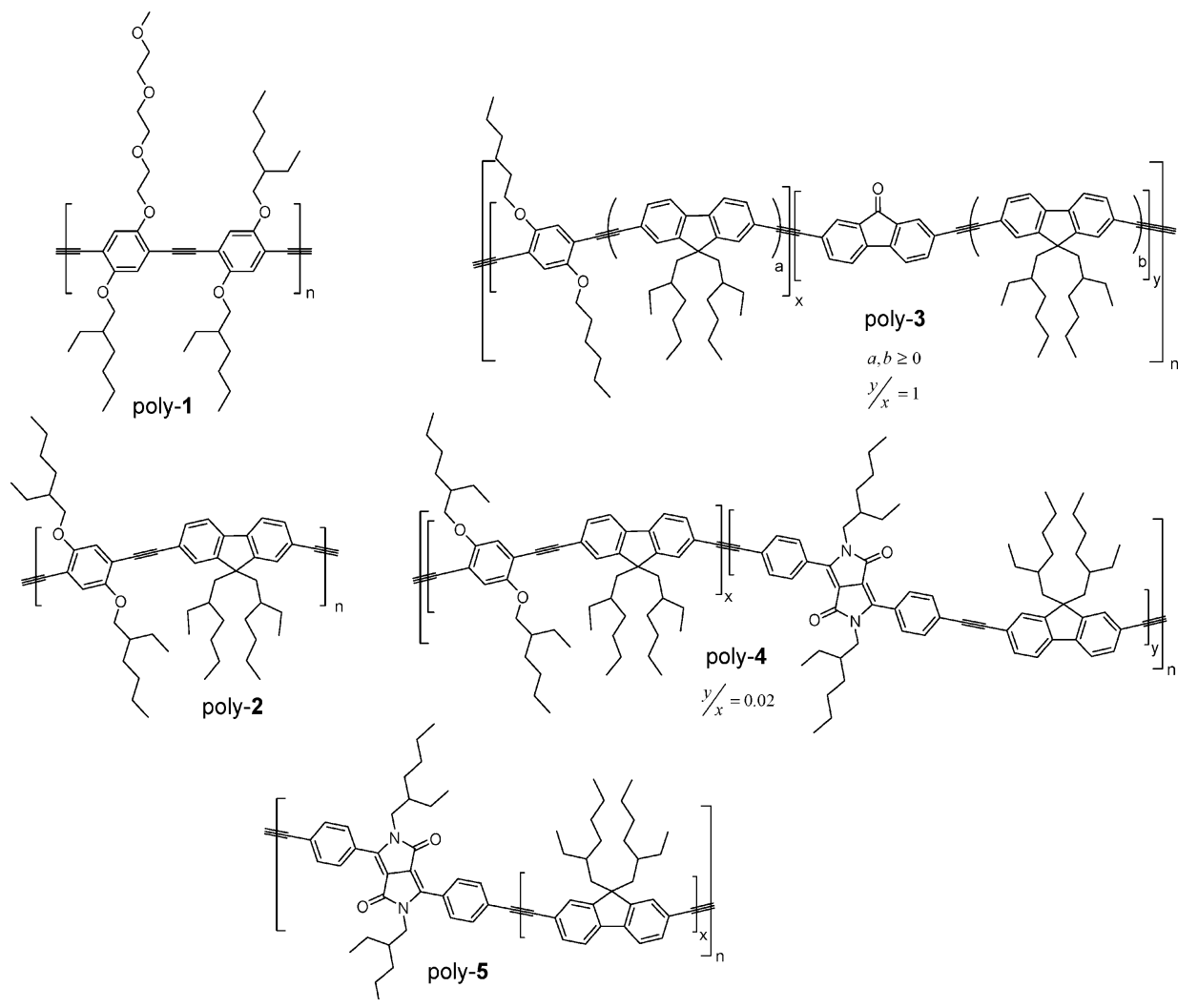

the absence of toluene, incomplete conversion to low molecular weight polymers occurred; possibly a small amount of organic solvent is required to ensure sufficient mixing of monomer and polymer throughout the polymerization. Higher amounts of solvent resulted in particle agglomeration. Residual amounts of toluene could be easily removed from the dispersions by either dialysis, owing to the partial solubility of toluene in water or by simply stirring the latex in an open vessel. Remarkably, by concentration (exposing the latex in a dialysis hose to a gentle stream of air), colloidally stable dispersions with high solids content could be obtained without coagulation, as demonstrated by a 15 wt $\%$ dispersion of poly-5.

The copolymerization of dibromo-substituted fluorenone or pyrrolopyrrole, respectively, afforded nanoparticles of poly(arylene ethynylene) (poly-3, poly-4, and poly-5) with covalently incorporated dyes. This enables the bathochromic adjustment of the particles' emission color with respect to the parent polymer via energy transfer from the polymer backbone to the dye, ${ }^{7 b, 14}$ while retaining the excitation wavelength due to the essentially very similar absorption properties of the polymer backbone (Table 3, and Figures S1 and S2 in Supporting Information). As illustrated for samples of different polymers poly-5 varying in the degree of incorporation of pyrrolo-pyrrole units (Figure 1), at $0.5 \mathrm{~mol} \%$ pyrrole-pyrrole incorporation virtually complete energy transfer and emission only from the dye repeat units is observed. Fluorescence quantum yields increase with dye incorporation, from $44 \%$ for poly[di(ethylhexyl)fluoreneethynylene] nanoparticles (i.e., poly-5 without incorporated dye) to $>60 \%$ (entry 5 ) under otherwise identical conditions. By comparison to physical blending, ${ }^{15}$ covalent incorporation excludes microphase separation or dye leakage, which can be problematic otherwise. Materials emitting multiple colors under single-wavelength excitation are advantageous for multiplex bioanalysis or biomedical imaging. To date, mainly inorganic quantum dots have been investigated. ${ }^{16}$ Studies of organic materials for multiplexed emission are comparatively scarce. Silica nanoparticles loaded with dye mixtures providing FRET or nanoparticles consisting of push-pull molecular systems providing intramolecular charge transfer while retaining the absorption band have been reported. ${ }^{17}$

Cell Uptake. The suitability of the conjugated polymer nanoparticles as biological markers was probed by live cell experiments. The as-obtained aqueous dispersions were found to be ammenable to dilution with growth medium without any agglomeration or precipitation of the nanoparticles, enabling incubation of adherent live HeLa cells with the desired amount of the fluorescent nanoparticles by simple medium exchange. Appropriate labeling of the cells was achieved by applying the 

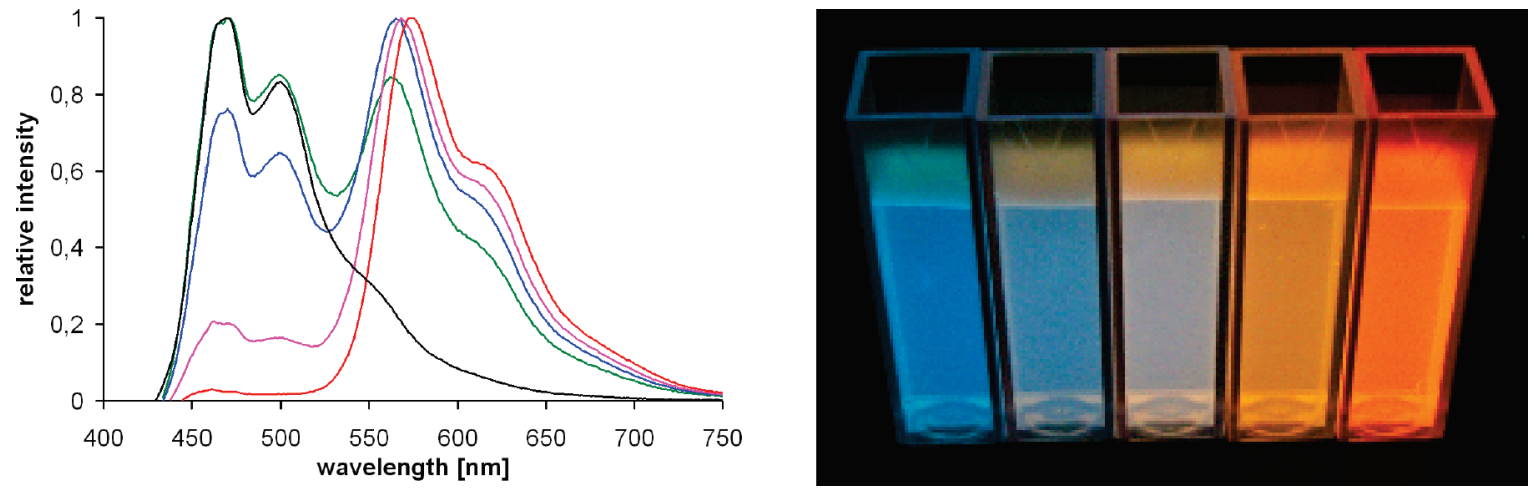

Figure 1. Fluorescence spectra (left; $\lambda_{\text {exc. }} 398 \mathrm{~nm}$ ) and optical appearance under UV light illumination (right, $\lambda_{\text {exc. }} 366 \mathrm{~nm}$ ) of aqueous nanoparticle dispersions of polymers poly- 5 with molar incorporations of $0 \%$ (black graph, and left dispersion in photograph), 0.015 (green), 0.05 (blue), 0.15 (mauve), and $0.5 \%$ of pyrrolo-pyrrole (red graph; this sample corresponds to entry poly-5 in Table 3 ). Molecular weights for all samples $M_{n}$ $8 \times 10^{4}-1 \times 10^{5} \mathrm{~g} \mathrm{~mol}^{-1}\left(M_{\mathrm{w}} / M_{\mathrm{n}} 3-4\right)$.
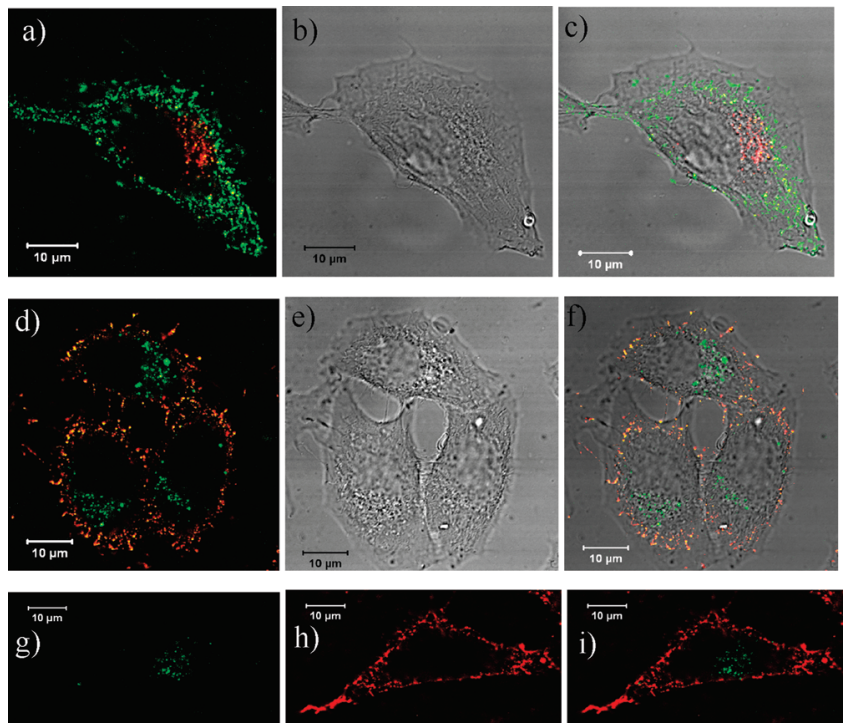

Figure 2. Micrographs of fixed HeLa cells labeled with conjugated polymer nanoparticles excited at $458 \mathrm{~nm}$. (a) Confocal fluorescence micrograph with two-channel detection (cf. Supporting Information), poly-1 (outside) and poly-4 (inside). (b) Brightfield image to (a). (c) Overlay of (a) and (b). (d) Confocal fluorescence micrograph with two-channel detection, poly-2 (inside); poly-4 (outside). (e) Brightfield image to (d). (f) Overlay of (d) and (e). (g and h) Spectrally resolved confocal fluorescence micrographs, poly-2 (inside) and poly-4 (outside). (i) Overlay of (g) and (h).

initial dispersion in a roughly $10^{3}$-fold dilution. Nanoparticles were effectively taken up by the live HeLa cells during incubation overnight and accumulated in the cytosol; no penetration into the nucleus was observed. To provide further evidence of the location of nanoparticles in the cell and to demonstrate that appropriate nanoparticles can be distinguished in optical microscopy after particle uptake by the live cells, the cells were fixed with paraformaldehyde and subsequently incubated with a second species of nanoparticles with a different emission color. Due to the fixation, the latter nanoparticles can no longer penetrate the cell, but adhered at the cell membrane, giving clear evidence that the first particle species is located inside the cell (Figure 2).

Further evidence for nanoparticle uptake is provided by labeling live cells in suspension, followed by seeding on coverslips and growing for another $24 \mathrm{~h}$ (Figure S4). This procedure allows the removal of excess nanoparticles, which remained in the supernatant after centrifugation. It is noteworthy that (a) over the course of the experiments no apoptotic cells

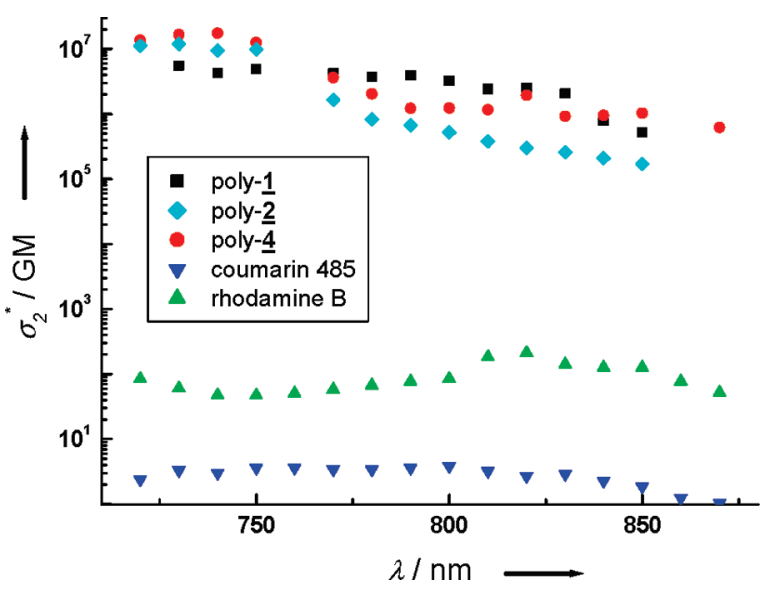

Figure 3. Semilogarithmic plot of two-photon action cross sections $\sigma_{2}{ }^{*}$ vs the excitation wavelength for poly-1, poly-2, poly-4, and two reference compounds.

were observed and (b) suspension-labeled cells adhered and grew normally. No conceivable adverse effect of any catalyst residues present (reasonably assuming that all $\mathrm{Pd}$ employed during particle synthesis resides in the particle, this amounts to a metal content of $\leq 3000 \mathrm{ppm} \mathrm{w} / \mathrm{w}$ in the particles) or SDS surfactant was observed. This contrasts the finding that SDSstabilized poly[(5-methoxy-2-ethylhexyloxy-phenylene)vinylene] (MEH-PPV) nanoparticles were toxic to cells at incubation times exceeding 2 h. $^{18}$ Studies of photostability of the nanoparticles under imaging conditions indicate a high stability toward bleaching. No noticeable decrease of fluorescence intensity was observed for nanoparticles in fixed cells upon continuous illumination over a period of $500 \mathrm{~s}$ (Figure S5).

Two-Photon Imaging. Two-photon action cross sections $\sigma_{2}{ }^{*}$ of poly-1, poly-2, and poly-4 nanoparticles (Figure 3) were determined on a custom-made microscope by focusing a modelocked Ti:sapphire laser into the aqueous nanoparticle dispersion and collecting the reflected fluorescence signal via an electron multiplying charge coupled device (EMCCD) camera as a function of excitation wavelength versus reference standards with known $\sigma_{2}{ }^{*}$ (see Supporting Information). ${ }^{19}$ The determined cross sections range from $10^{6}$ to $10^{7}$ Göppert-Meyer units. Thus, they are several orders of magnitude brighter than inorganic quantum dots or conventional organic fluorophores (this also applies to brightness with respect to unit volume. The data agrees with previous observations on conjugated polymer nanoparticles [7d,9], taking particle volume into account). ${ }^{20}$ Indeed, single nanoparticles are readily detected by confocal 

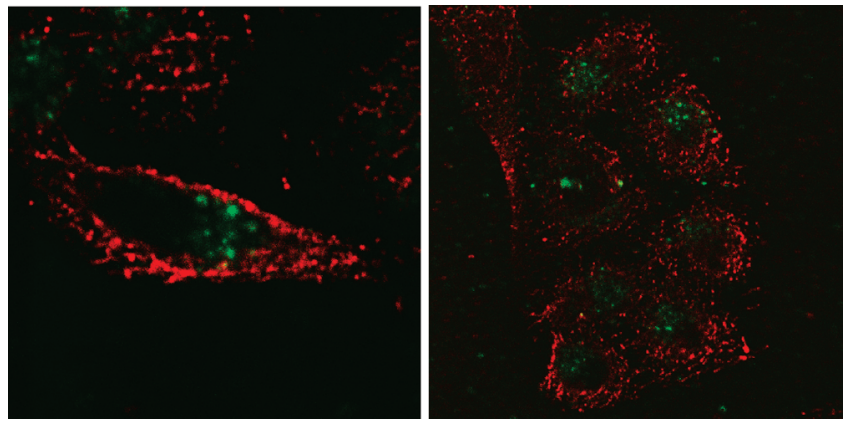

Figure 4. Confocal fluorescence micrographs of fixed HeLa cells labeled with conjugated polymer poly-1 (green, inside) and poly-4 (red, outside) nanoparticles excited at $780 \mathrm{~nm}$.

microscopy (Figure S3). As anticipated for a nonlinear excitation, $\sigma_{2} *$ does not feature a distinict wavelength dependence in the spectral range studied, which is advantageous for imaging concerning the choice of excitation source.

The particle system reported allows for multicolor cell imaging and differentiation of different particle types with twophoton excitation in the NIR regime (Figure 4).

\section{Summary and Conclusions}

In conclusion, Sonogashira coupling in aqueous miniemulsion affords particles compatible with live cells and suited as ultrabright probes for cell imaging. Tuning the emission color of the particles via dyes covalently incorporated during miniemulsion polymerization allows for differentiation of the location of different particle species in cells, demonstrated for both linear and nonlinear excitation. The approach of generation of the appropriate conjugated polymer nanoparticles directly by polymerization in a disperse aqueous system opens a broader perspective for accessing structured nanoparticles, for example, with functional interiors and peripheries. Due to the $\mathrm{A}_{2}+\mathrm{B}_{2}$ type step-growth nature of the polymerization reaction, Sonogashira coupling is suited for the preparation of a broad variety of polymers with variable optical properties by combination of monomers with donor and acceptor properties, respectively.

Acknowledgment. Financial support by the DFG (Me 1388/ 7-1) is gratefully acknowledged. We thank D. Träutlein and A. Leitenstorfer for fruitful discussions.

Supporting Information Available. Experimental details of monomer syntheses and determination of two-photon action cross sections; additional spectral, microscopy, and DLS data; GPC chromatogram. This material is available free of charge via the Internet at http://pubs.acs.org.

\section{References and Notes}

(1) Kietzke, T.; Neher, D.; Landfester, K.; Montenegro, R.; Guntner, B.; Scherf, U. Nat. Mater. 2003, 2, 408-412.
(2) Michalet, X.; Pinaud, F. F.; Bentolila, L. A.; Tsay, J. M.; Doose, S.; Li, J. J.; Sundaresan, G.; Wu, A. M.; Gambhir, S. S.; Weiss, S. Science 2005, 307, 538-544.

(3) Akbulut, M.; Ginart, P.; Gindy, M. E.; Theriault, C.; Chin, K. H.; Soboyejo, W.; Prud'homme, R. K. Adv. Funct. Mater. 2009, 19, 718725 .

(4) Sokolov, I.; Naik, S. Small 2008, 4, 934-939.

(5) (a) Tian, Z.; Shaller, A. D.; Li, A. D. Q. Chem. Commun. 2009, 180182. (b) Tallury, P.; Kar, S.; Bamrungsap, S.; Huang, Y.-F.; Tan, W.; Santra, S. Chem. Commun. 2009, 2347-2349.

(6) (a) Yasukuni, R.; Asahi, T.; Sugiyama, T.; Masuhara, H.; Silwa, M.; Hofkens, J.; De Schryver, F. C.; Van der Auweraer, M.; Herrmann, A.; Müllen, K. Appl. Phys. A: Mater. Sci. Process. 2008, 93, 5-9. (b) Abbel, R.; Van der Weegen, R.; Meijer, E. W.; Schenning, A. P. H. J. Chem. Commun. 2009, 1697-1699.

(7) (a) Wu, C.; Bull, B.; Szymanski, C.; Christensen, K.; McNeill, J. ACS Nano 2008, 2, 2415-2423. (b) Baier, M. C.; Huber, J.; Mecking, S. J. Am. Chem. Soc. 2009, 131, 14267-14273. (c) Landfester, K.; Montenegro, R.; Scherff, U.; Güntner, R.; Asawapirom, U.; Patil, S.; Neher, D.; Kietzke, T. Adv. Mater. 2002, 14, 651-655. (d) Rahim, N. A. A.; McDaniel, W.; Bardon, K.; Srinivasan, S.; Vickerman, V.; So, P. T. C.; Moon, J. H. Adv. Mater. 2009, 21, 3492-3496. (e) Howes, P.; Thorogate, R.; Green, M.; Jickells, S.; Daniel, B. Chem. Commun. 2009, 2490-2492. (f) Yu, J.; Wu, C.; Sahu, S. P.; Fernando, L. P.; Szymanski, C.; McNeill, J. J. Am. Chem. Soc. 2009, 131, 1841018414. (g) Howes, P.; Green, M.; Levitt, J.; Suhling, K.; Hughes, M. J. Am. Chem. Soc. 2010, 132, 3989-3996.

(8) Mailänder, V.; Landfester, K. Biomacromolecules 2009, 10, 23792400.

(9) Wu, C.; Szymanski, C.; Zachary, C.; McNeill, J. J. Am. Chem. Soc. 2007, 129, 12904-12905.

(10) Pecher, J.; Mecking, S. Chem. Rev. 2010, doi: 10.1021/cr100132y.

(11) Szymanski, C.; Wu, C.; Hooper, J.; Salazar, M. A.; Perdomo, A.; Dukes, A.; McNeill, J. J. Phys. Chem. B 2005, 109, 8543-8546.

(12) Pecher, J.; Mecking, S. Macromolecules 2007, 40, 7733-7735.

(13) Moon, J. H.; McDaniel, W.; MacLean, P.; Hancock, L. F. Angew. Chem., Int. Ed. 2007, 46, 8223-8225.

(14) Ego, C.; Marsitzky, D.; Becker, S.; Zhang, J.; Grimsdale, A. C.; Müllen, K.; MacKenzie, J. D.; Silva, C.; Friend, R. H. J. Am. Chem. Soc. 2003, 125, 437-443.

(15) (a) Wu, C.; Peng, H.; Jiang, Y.; McNeill, J. J. Phys. Chem. B 2006, 110, 14148-14154. (b) Wu, C.; Zheng, Y.; Szymanski, C.; McNeill, J. J. Phys. Chem. C 2008, 112, 1772-1781. (c) Kong, F.; Sun, Y. M.; Yuan, R. K. Nanotechnology 2007, 18, 265707-1265707-5. (d) Kong, F.; Wu, X. L.; Huang, G. S.; Yuan, R. K.; Chu, P. K. Thin Solid Films 2008, 516, 6287-6292. (e) Harbron, E. J.; Davis, C. M.; Campbell, J. K.; Allred, R. M.; Kovary, M. T.; Economou, N. J. J. Phys. Chem. C 2009, 113, 13707-13714.

(16) Bruchez, M. P.; Hotz, C. Z. Quantum Dots; Humana Press: Totowa, NJ, 2007.

(17) (a) Wang, L.; Tan, W. Nano Lett. 2006, 6, 84-88. (b) Ishow, E.; Brosseau, A.; Clavier, G.; Nakatani, K.; Tauc, P.; Fiorini-Debuisschert, C.; Neveu, S.; Sandre, O.; Léaustic, A. Chem. Mater. 2008, 20, 65976599.

(18) Green, M.; Howes, P.; Berry, C.; Argyros, O.; Thanou, M. Proc. $R$. Soc. A 2009, 465, 2751-2759.

(19) Makarov, N. S.; Drobizhev, M.; Rebane, A. Opt. Express 2008, 16, 4029-4047.

(20) Larson, D. R.; Zipfel, W. R.; Williams, R. M.; Clark, S. W.; Bruchez, M. P.; Wise, F. W.; Webb, W. W. Science 2003, 300, 1434-1436.

BM100854A 